\title{
PA-142 ESTABLISHMENT OF A SUB-REGIONAL ETHICS COMMITTEE IN CENTRAL AFRICA TO ADDRESS THE NEEDS OF MULTICOUNTRY PROJECTS: AN OCEAC INITIATIVE
}

Sylvie Kwedi Nona. OCEAC, Cameroon

\subsection{6/bmjgh-2016-000260.168}

Background The Universal Declaration on Bioethics and Human Rights, adopted by UNESCO, requires that governments establish National Ethics Committees (NECs) capable of reviewing ethical and scientific aspects on research involving human beings. These NECs are government gatekeepers tasked with ensuring that research conducted in their territories is in compliance with national and international ethics requirements. In Central Africa, NECs are lacking in some countries, barely functional in others either crippled by lack of expertise, scarce opportunities for training or by an environment not conducive to quality and ethical research. To remedy this shortcoming, OCEAC was awarded an EDCTP grant to put in place a common Ethics Committee for Central Africa.

Methods Six designated representatives of Ministries of Health, with appropriate background and skills, from Cameroon, Chad, Equatorial Guinea, Gabon, Republic of Congo, and the Central African Republic were selected to be members of the subregional Ethics Commitee. In order to ensure the proper composition of this committee, ethics experts originating from central Africa were selected through a call for candidates widely published in various ethics and research networks in the subregion.

Results CERSAC (Comité d'Ethique de la Recherche et de la Santé en Afrique Centrale) is the designation of the resulting sub-regional Ethics Committee, assembling fifteen members from the six CEMAC countries and the Democratic Republic of Congo. Since 2014, CERSAC has provided streamlined reviews of health research projects conducted in more than one Central Africa country. A total of 37 local emerging-career researchers and ethics committee members were trained.

Conclusions CERSAC enhances the ethical conduct and social value of research and optimises the protection of human research participants for communities in dire need. The committee also provides a harmonised platform to address ethical challenges related to the conduct and output of health research in Central Africa. 